\title{
Influence of texture and microstructure on the reactivity of aluminum powders.
}

Pierre-Henry Esposito ${ }^{1}$, Christine Leroux ${ }^{2}$, Vasile Heresanu ${ }^{3}$, Thomas Neisius ${ }^{4}$, Véronique Madigou ${ }^{2}$, Renaud Denoyel $^{1}$, Marie-Vanessa Coulet ${ }^{1 *}$

1 Aix-Marseille Univ., CNRS, MADIREL UMR 7246, Marseille, France

2 Université de Toulon, AMU, CNRS, IM2NP UMR 7334, Toulon, France

3 Aix Marseille Univ., CNRS, CINaM UMR 7325, Marseille, France

4 Aix Marseille Univ., CNRS, Fédération de Chimie, Marseille, France

* corresponding author, vanessa.coulet@univ-amu.fr, +0033413551809

\begin{abstract}
Aluminum powders are commonly used in energetics materials and it is possible to improve their reactivity by preparing them as nanopowders. In this article, it is shown that high-energy ball milling can be used to tune the reactivity of nanoflakes. Several nanopowders are synthesized using three different grinding ball diameters $(5 \mathrm{~mm}, 10 \mathrm{~mm}$ and $15 \mathrm{~mm})$. The powders are characterized in terms of morphology, structure and microstructure. Changing the diameter of the grinding balls results in powders with different characteristics. Among the three diameters used, an optimum is found for powders synthetized with $10 \mathrm{~mm}$ diameter balls: they possess the highest specific area, the smallest aluminum crystallites and the lowest amount of deformation. The reactivity of the various nanopowders, evaluated using thermal analysis under air, is shown to be dependent on both textural and microstructural properties of the powders. Such considerations on the microstructural properties of nanopowders are of utmost importance in the quest for the best materials for energetics applications.
\end{abstract}




\section{Introduction}

Aluminum powders are found in various industrial applications from construction to aerospace engineering. They can be used in the formulation of porous concrete [1], fingerprint detection compounds [2], coatings and inks $[3,4]$ and hydrogen generation devices $[5,6]$. Thanks to their high reactivity properties toward oxygen, they are also widely used in thermites formulations [7,8], as pyrotechnics or explosive component [9-11] and as fuel in rocket propellants [12-14]. In those latter applications, the use of nanosized powders is reported to improve reaction efficiency or, in the case of propellant, to avoid ignition delays. Many elaboration methods are proposed to produce reactive aluminum nanopowders. Wire-electro-explosion [15-17], plasma process $[18,19]$, laser or induction heating evaporation [20-22] are the mostly used techniques to produce spherical shaped nanoparticles. High-energy ball-milling is also a recognized method for the synthesis of reactive powders $[23,24]$. In this case, due to the ductility of aluminum, the as-synthesized powders have a flake morphology.

Regardless their synthesis, the Al particles have a core-shell structure in which a thin oxide layer of alumina passivates the metallic aluminum core. This protective shell, which is initially amorphous, has been reported to play an important role in the low heating rate regime of oxidation. Indeed, in the early 2000 , the oxidation of aluminum micrometric powders has been shown to be a stepwise mechanism governed by the polymorphic transitions occurring in the alumina shell $[25,26]$. The reactivity of aluminum powders is commonly studied by means of thermogravimetric analyses (TGA) under oxidative atmosphere (Air, Oxygen) and several criteria were introduced $[27,28]$ to quantify and compare the reactivity between samples. Figure 1 shows typical TGA curves obtained for spherical powders in the same experimental conditions and having different particle sizes (micrometric and nanometric). It can be observed that the mass gain versus temperature undergoes several steps whose height depends on the size of the particles. The onset temperature of the first oxidation step $\left(\mathrm{T}_{1}\right)$, the mass gain at the first step $\left(\mathrm{M}_{1}\right)$ and the total mass gain at the end of the oxidation process $\left(\mathrm{M}_{\mathrm{tot}}\right)$ can be used to compare the reactivity of the powders. It is generally admitted that, for low heating rates, $\mathrm{M}_{1}$ is higher for nanopowders, which is of interest for enhanced combustion properties [12,14,29]. Consequently, due to the higher proportion of alumina in the nanopowders, $\mathrm{M}_{\mathrm{tot}}$ is lower for nanopowders. It is thus mandatory for applications in propellants to find a compromise between the gain in reactivity brought by the size reduction and the higher amount of alumina which could limit the combustion capacity. 


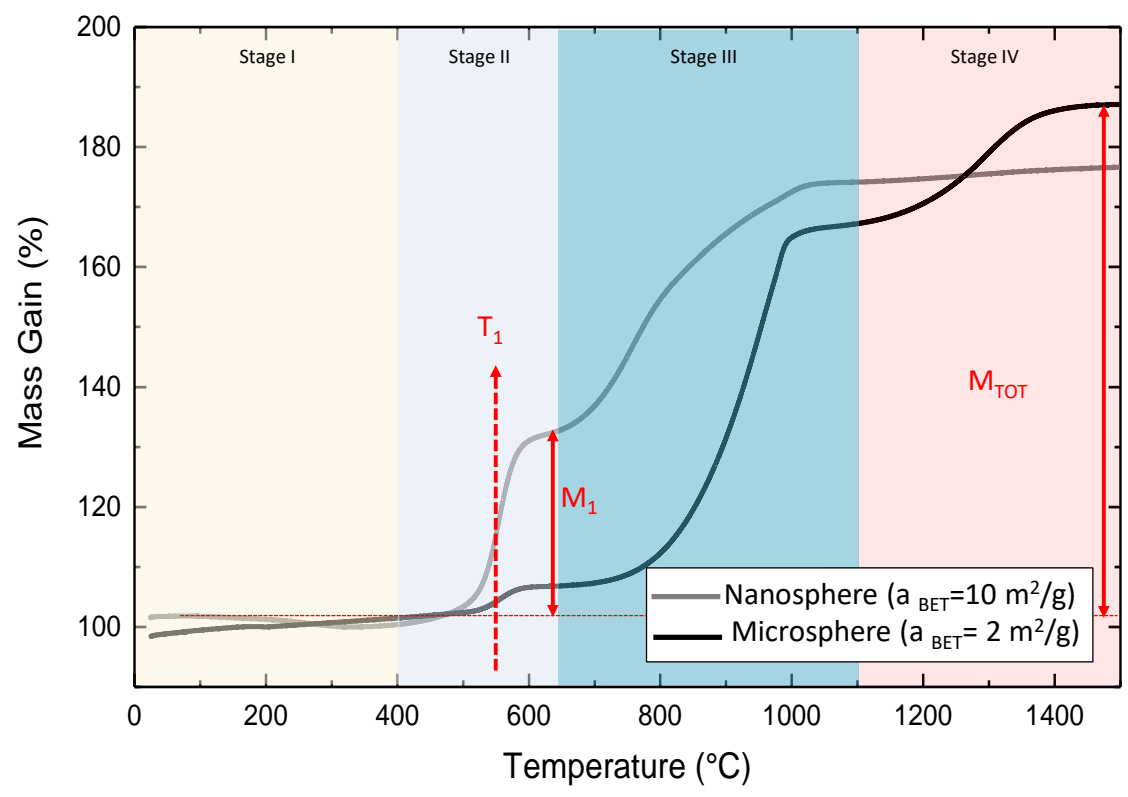

Figure 1: Example of thermogravimetry analyses performed up to $1500^{\circ} \mathrm{C}$ on micro- and nanopowders having a sphere morphology. The various quantities that are used to compare the powder reactivity are shown on the graph. $\mathrm{T}_{1}$ is the temperature of the first oxidation step, $\mathrm{M}_{1}$ the mass gain at the first step and $\mathrm{M}_{\mathrm{tot}}$, the total mass at $1500^{\circ} \mathrm{C}$, i.e. at the end of the oxidation process (adapted from ref [29]).

The relationship between $T_{1}$ and the particle size is not so straightforward and seems to depend on the morphology. Indeed, no major changes in $\mathrm{T}_{1}$ have been clearly evidenced in the case of spherical powders [29]. At contrary, for particles with a flake morphology, a lowering of $T_{1}$ is observed when the particle size decreases [30]. This may be of interest for applications since lower $\mathrm{T}_{1}$ could result in lower ignition temperatures. There is thus still a need for a better understanding on the relationship between the above defined criteria and the powder characteristics in terms of shape, size, structure and microstructure.

The aim of the present contribution is to understand how texture and microstructure act on the reactivity of the powders in the case of nanoflakes. This is done by studying three different powders which have been synthetized by high energy ball milling using different diameters for the grinding balls. The as-synthesized powders are first characterized in terms of texture (morphology, size distribution and specific surface area) using various complementary techniques ranging from gas adsorption up to transmission electron microscopy (TEM). The microstructure is analyzed by means high-resolution TEM and X-ray diffraction. Finally, the 
reactivity of the powders and their oxidation behavior is discussed according to the textural and microstructural characteristics of the powders.

\section{Methods}

\subsection{Sample preparation}

Aluminum powder from Alfa Aesar (purity 99.8\%) was used as the starting material. Milling was performed with a high-energy planetary ball mill (P4 Fritsch) using vials and balls made of stainless steel. The rotation speeds of vials and plateau were fixed to $800 \mathrm{rpm}$ and $400 \mathrm{rpm}$ respectively. They were moving in opposite directions. Paraffin oil was added into the vials in order to minimize cold welding and to increase the milling efficiency $[8,31,32]$. According to previous optimization procedures [24,30], the total milling time was fixed to $16 \mathrm{~h}$ by alternating 10 minutes milling and 2 minutes of rest. Such a total milling time is sufficient to reach the steady state as confirmed by several authors [33,34]. Air introduction during the milling is a key factor to obtain reactive aluminum powders with high specific surface areas [24]. In this work, dry air was directly introduced inside the bowl using special lids with valves. The air was renewed in the vials every hour of milling as proposed in [24]. In order to investigate the influence of the ball diameter onto the resulting powders, 3 different ball diameters were used: 5, 10 and $15 \mathrm{~mm}$. The same powder to ball mass ratio (also called charge ratio) equal to 1:16 was used for all millings. In the following, the synthetized powders are labeled according to the ball diameter: B05, B10 and B15.

\subsection{Characterization methods}

Before characterization, the paraffin oil was removed from the powders by realizing successive washes with ultra-pure solvents (toluene, acetone and ethanol). The quantity of metallic aluminum in the powders was quantified using a volumetric titration technique inspired from the work of Antipina et al. [35]. This method consists in measuring the volume of dihydrogen produced during the reaction between the aluminum powder and a sodium hydroxide solution. To perform the experiment, around $10 \mathrm{mg}$ of powder was mixed with $10 \mathrm{~mL}$ of a $0.2 \mathrm{~mol} / \mathrm{L}$ sodium hydroxide solution. The volume was measured every 30 minutes and was shown to attain a plateau after 12 hours. The measurement error was evaluated by repeating the analyses three times for 
each sample. The metallic aluminum content was obtained after renormalization using the starting powder Alfa Aesar.

The specific surface area of the powders was derived from gas adsorption analyses. Around $1 \mathrm{~g}$ of powder was used for the experiments. Before the sorption measurement, each sample was outgassed at a pressure below $1 \mathrm{~Pa}$ overnight at $120^{\circ} \mathrm{C}$ in order to remove adsorbed impurities. Nitrogen adsorption-desorption isotherms were measured at $77 \mathrm{~K}$ with an ASAP 2010 instrument from Micromeritics.

Powders morphology was analyzed using a Hitachi S-4800 scanning electron microscope (SEM). Images were acquired in secondary electron mode. For each observation, a small amount of powder was deposited on a double-faced carbon tape.

The dimensions of the flakes and the thickness of the alumina layer were evaluated by means of transmission electron microscopy (TEM) using a FEI TECNAI G2 with a LaB 6 source. This evaluation, done on 150-200 particles, is sufficient to give an idea of the evolution of the size between the three powders. EFTEM-EELS measurements were performed using a FEI TITAN 80-300 TEM equipped with an image corrector and a GATAN TRIDIEM imaging filter for the acquisition of energy filtered (EF) images. The acceleration voltage was set to $200 \mathrm{kV}$. The acquisitions were done at $15 \mathrm{eV}$ (characteristic bulk plasmon energy for aluminum) and at $24 \mathrm{eV}\left(\alpha-\mathrm{Al}_{2} \mathrm{O}_{3}\right.$ plasmon peak) with a width of $4 \mathrm{eV}$ of the energy selecting slit. TEM sample grids preparation consisted in ultrasonic dispersing of a small amount of powder in absolute methanol. After approx. 20 minutes of decantation, a drop was deposited on a holey carbon grid and put in an oven at $80^{\circ} \mathrm{C}$ for half an hour to remove the solvent.

The reactivity of the powders was investigated using the Setsys Evolution apparatus of SETARAM. It allows performing simultaneously thermogravimetric analysis and differential thermal analysis (TGA/DTA) up to $1200^{\circ} \mathrm{C}$ and simple thermogravimetric analyses (TGA) up to $1500^{\circ} \mathrm{C}$. A dry air flow $(20 \mathrm{ml} / \mathrm{min})$ was chosen to study the thermal oxidation of powders. All experiments were conducted at a constant heating rate of $2^{\circ} \mathrm{C} / \mathrm{min}$ from room temperature up to $1200^{\circ} \mathrm{C}$ (TGA/TDA measurements) or up to $1500^{\circ} \mathrm{C}$ (TGA only). DTA was calibrated over the whole investigated temperature range by determining the melting of pure substances (In, $\mathrm{Sn}, \mathrm{Al}$ and $\mathrm{Ge}$ ) at various heating rate under $\mathrm{Ar}$ atmosphere. This standard procedure allows a calibration in temperature and in energy. 
In the following, three reactivity parameters will be used to compare the powders: $T_{1}$ as the onset temperature of the first oxidation step, $M_{1}$ as the mass gain at the first step and $\mathrm{M}_{\mathrm{tot}}$ as the total mass gain at the end of the oxidation process.

At last, the structure and microstructure of the powder was studied using X-ray diffraction (XRD). The patterns were acquired in transmission mode using a powder INEL diffractometer with a monochromatic $\mathrm{CuK}_{\alpha 1}$ radiation $(\lambda=0.15406 \mathrm{~nm})$. This diffractometer is equipped with a CPS120 curved detector, which was positioned in order to cover an angular range between $30^{\circ}$ and $140^{\circ}$ by steps of $0.029^{\circ}$. The samples were filled in $0.5 \mathrm{~mm}$ glass capillaries and the acquisition time was set to 1800 seconds.

\section{Results and discussion}

\subsection{Texture}

SEM and TEM images (Fig. 2) confirm the flake morphology usually obtained by milling aluminum powders. Larger flakes are observed for B05 powders (Fig.2a) than for B10 (Fig.2b) and B15 (Fig.2c) powders. For all the samples, a quite large size distribution is observed but the larger flakes consist in the agglomeration of smaller ones as proven by the TEM image presented on Fig. $2 \mathrm{~d}$ on which a local rolling up of the supporting carbon film allowed the observation of nanoflakes edge. It is however very difficult to measure the thickness of the flakes with TEM but thicknesses smaller than $50 \mathrm{~nm}$ can be observed.

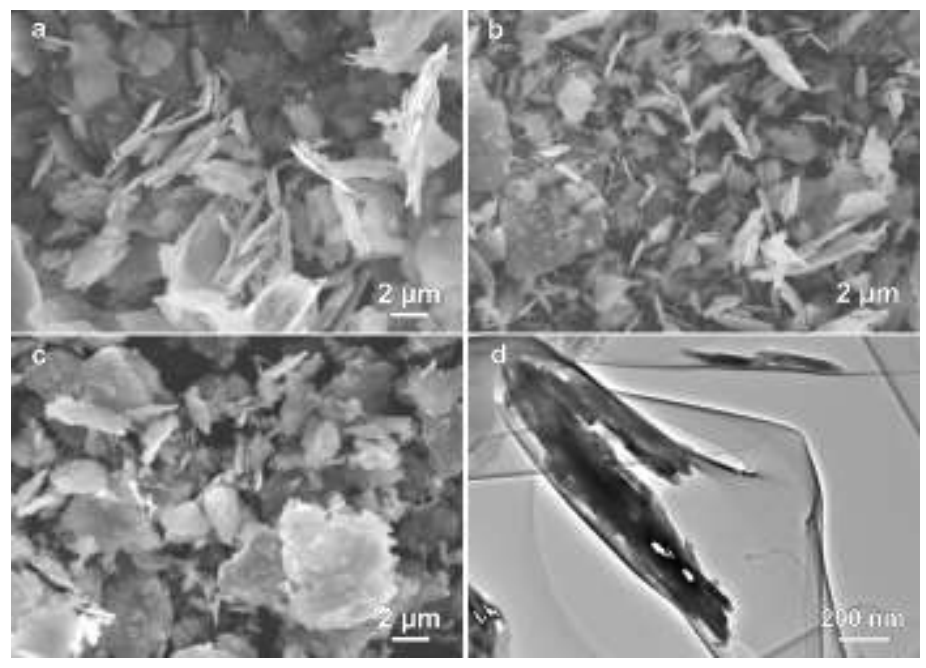

Figure 2: Nanoflake morphology of the particles evidenced by electron microscopy. SEM images of B05 (a), B10 (b) and B15 (c) powders. (d) TEM image of B10 powder that shows the stacking of the nanoflakes and the small thickness of the flakes. 
In order to a quantitative analysis of -quantify the dimensions of the flakes, they were assimilated to parallelepipeds with length $L$, width $W$ and thickness $T$. From TEM observation, the only quantities that can be measured are L and W. The images presented in Fig. 3 give an example for each powder of the determination of $\mathrm{L}$ and $\mathrm{W}$. The error in the total area of the flake done by such a simplification is evaluated to $8.5 \%$. The results of image analyses are given in the histograms of Fig.3.
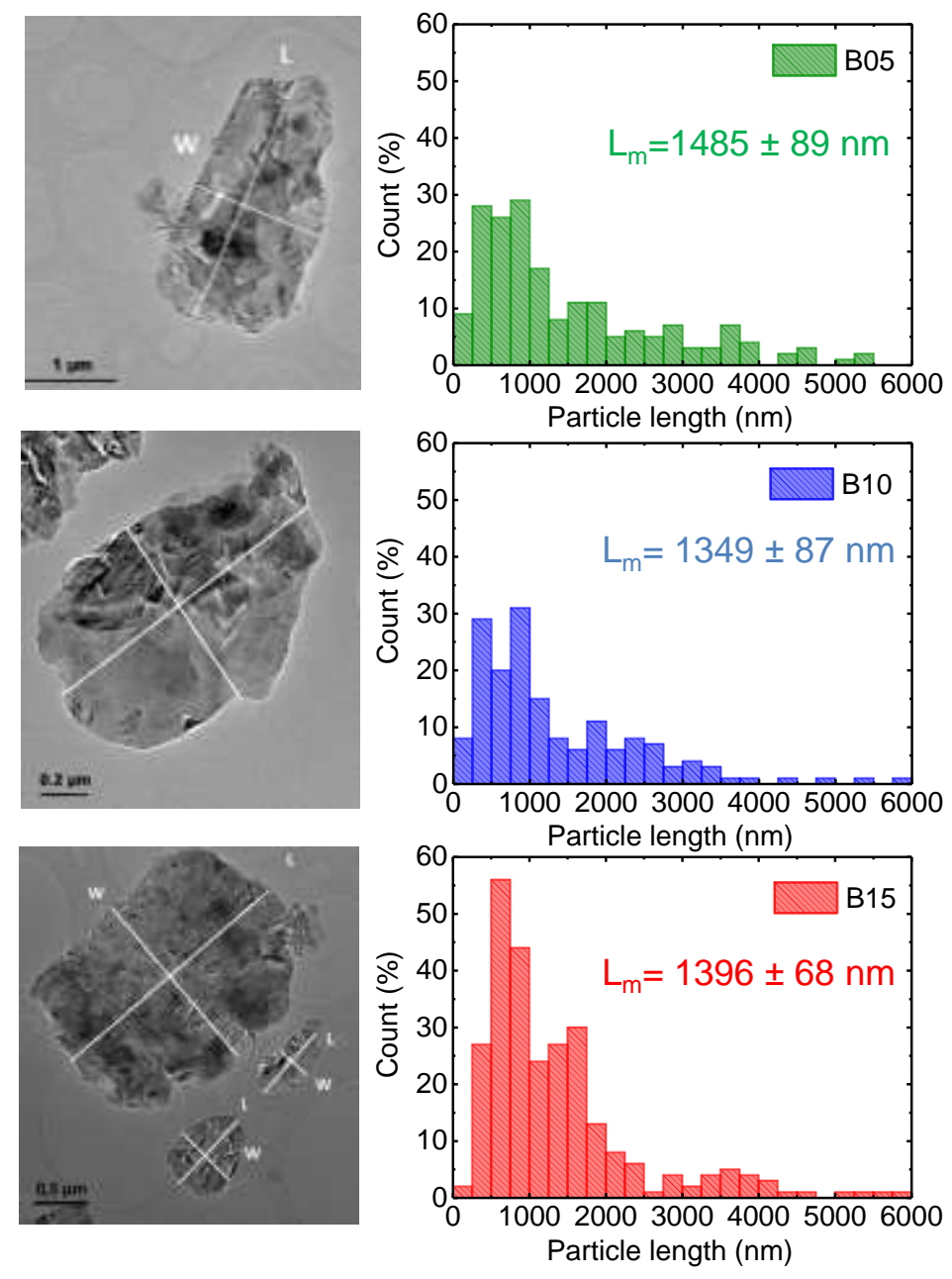
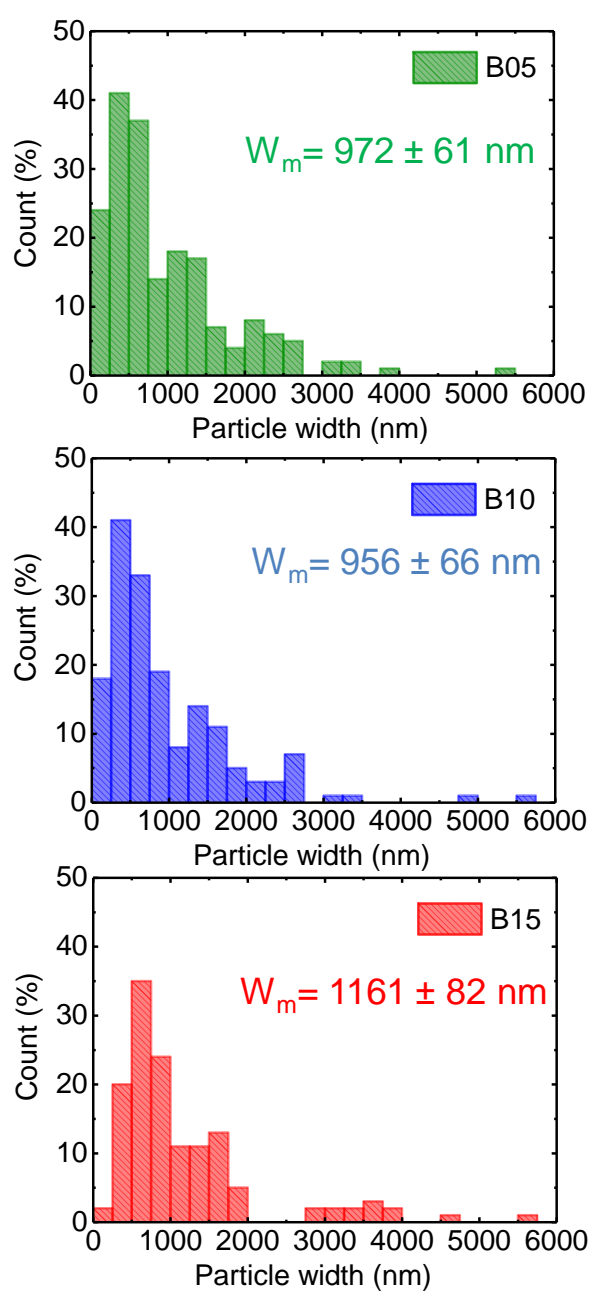

Figure 3: Typical TEM image of the particles (first column) and corresponding histograms of the particle length L (second column) and width W (third column) for the powders B05 (first line), B10 (second line) and B15 (third line). The mean value of the distribution and the standard error of the mean value are given on each histogram

It is worth noting that, whatever the grinding ball diameter, all the powders have dimensions within the same order of magnitude around $1 \mu \mathrm{m}$. It seems that slightly larger widths are observed for B15 powders, which would be consistent with a milling with larger balls diameters [48]. 
Nitrogen adsorption isotherms are presented in Fig.5.a. They belong to the type II of the IUPAC classification [36] which is characteristic of non-porous or macroporous materials. The adsorption uptake at $\mathrm{P} / \mathrm{P} 0=0.5$ for $\mathrm{B} 10$ and B15 is almost twice the one of B05, which suggests that B10 and B15 powders have smaller particle sizes than B05. The BET equation was used to calculate the specific surface area of powders $a_{B E T}$. As seen in Fig.5.b, B10 sample possesses the highest $a_{B E T}$ which suggests that there is an extremum for the evolution of surface area as a function of the diameter of the grinding balls. The values obtained for $a_{B E T}$ are of the same order of magnitude as those generally reported in literature for spherical nanopowders. For instance, the socalled ALEX powders produced by wire electro explosion, have a specific surface area around $11 \mathrm{~m}^{2} / \mathrm{g}[37,38]$, while values around $20 \mathrm{~m}^{2} / \mathrm{g}$ can be reached for the so-called HEIBE powders produced by ion beam evaporation process [20]. High-energy ball milling thus allows to produce powders within a wide range of specific surface area ranging from a few $\mathrm{m}^{2} / \mathrm{g}[30]$ up to more than $20 \mathrm{~m}^{2} / \mathrm{g}$.
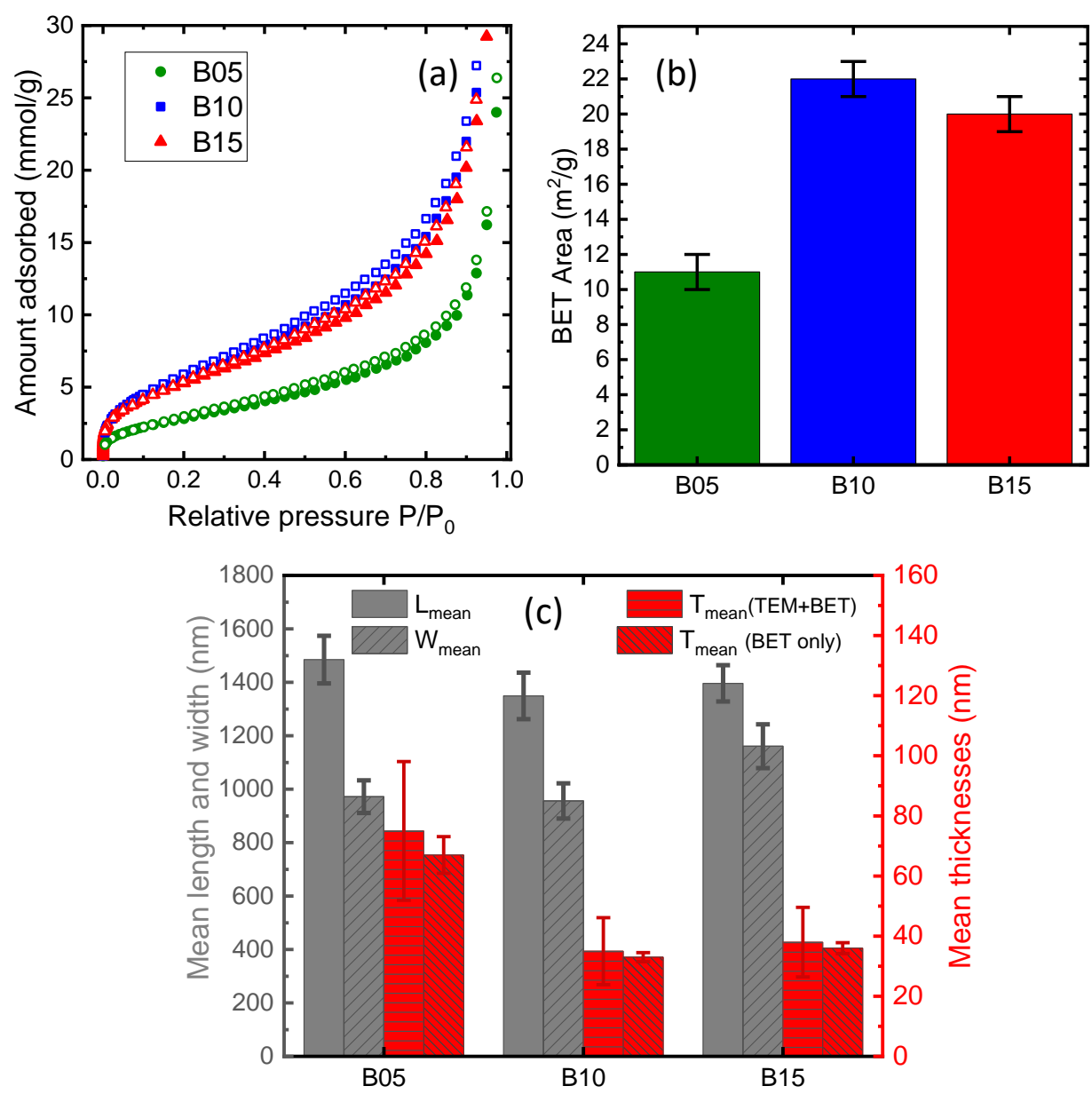

Figure 5: (a) Nitrogen adsorption/desorption isotherms performed at $77 \mathrm{~K}$ for the samples B05, B10 and B15 Full symbols correspond to adsorption and the open symbol to desorption. (b) BET area for B05, B10 and B15. (c) Summary of the mean dimensions obtained for the flakes. 
By combining TEM image analysis and BET areas deduced from nitrogen adsorption measurements, an estimation of the mean thickness of the flakes can be done. One can write:

$$
a_{\text {BET }}=\frac{S_{\text {flake }}}{\rho_{\text {flake }} V_{\text {flake }}}=2 \frac{T_{m} L_{m}+T_{m} W_{m}+W_{m} L_{m}}{\rho_{\text {flake }}\left(L_{m} W_{m} T_{m}\right)}
$$

With $S_{\text {flake }}$, the surface of the flake, $\rho_{\text {flake }}$ its density, $\mathrm{V}_{\text {flake }}$ its volume. For the density, the presence of the alumina layer is taken into account using the quantity of metallic aluminum obtained by volumetry (see table 1). The obtained mean values for the flake thicknesses $T_{m}$ are given in Fig.5.c together with the mean dimensions $L_{m}$ and $W_{m}$ obtained from TEM analysis. It can be observed that, whatever the diameter of the grinding balls, the nanometer scale is achieved for the flake thicknesses $T_{m}$ since the values are all below $100 \mathrm{~nm}$

In the case of flake shaped particles having large basal surfaces as compared to their thickness, the thickness can be written:

$$
a_{B E T} \approx \frac{2}{\rho_{\text {flake }} T_{m}}
$$

As seen on Fig.5, the values obtained using this rough assumption are in very good agreement with the ones obtained using the dimensions obtained for TEM image analysis.

Finally, high Resolution TEM (HRTEM) measurements allow evidencing the core-shell structure of Al particles as well as the amorphous nature of the surrounding alumina, as shown in Fig.4. The alumina thickness $t$ was measured for each sample over $\sim 100$ particles. The obtained values are presented in the histograms of Fig.4. Within the statistics of the present study, no differences are observed between the 3 powders. Interestingly the alumina thickness varies from $2 \mathrm{~nm}$ up to $6 \mathrm{~nm}$ but is still amorphous. Such dispersion in the thickness of the alumina layer are a specificity of milled powder and might be of interest for the reactive properties as it will be discussed below. 

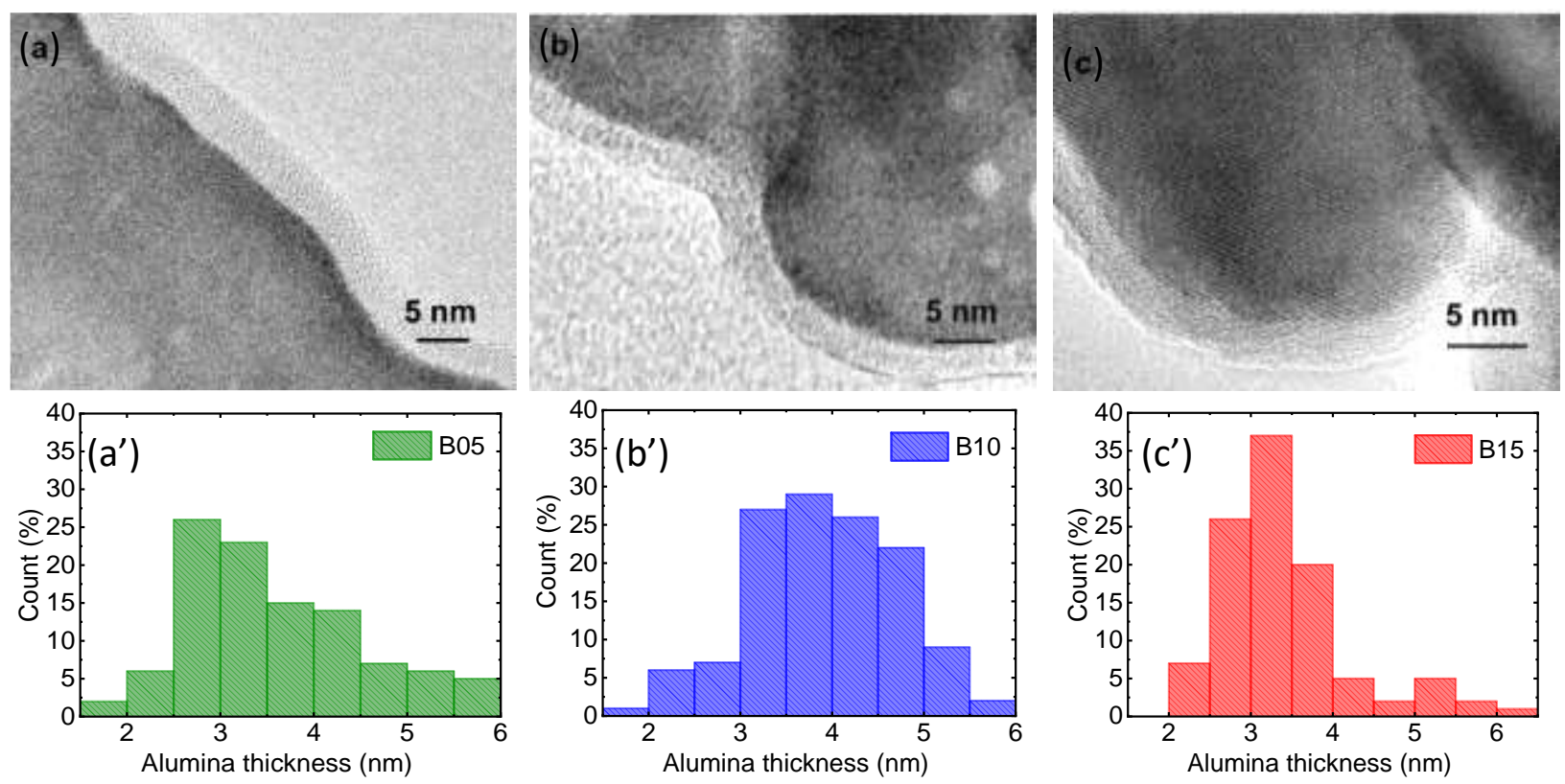

Figure 4: HREM images of aluminum particles, taken along directions near [011] and showing the amorphous alumina layer that surrounds the aluminum core for B05 (a), B10 (b) and B15 (c) powders. The histograms obtained for the alumina thickness are given for each powder (a',b' and c').

\subsection{Microstructure}

TEM was used to access the microstructure of the aluminum core. As illustrated in Fig.6.a and 6.b, the flakes are polycrystalline and preferentially oriented along [110] directions. Electron diffraction patterns from different grains building the flake (Fig. 6.a), correspond to [110] zone axes, with a slight misorientation from one grain to another. This is also evidenced in the high-resolution image shown in Fig.6b, where three grains with [110] orientation are imaged. 

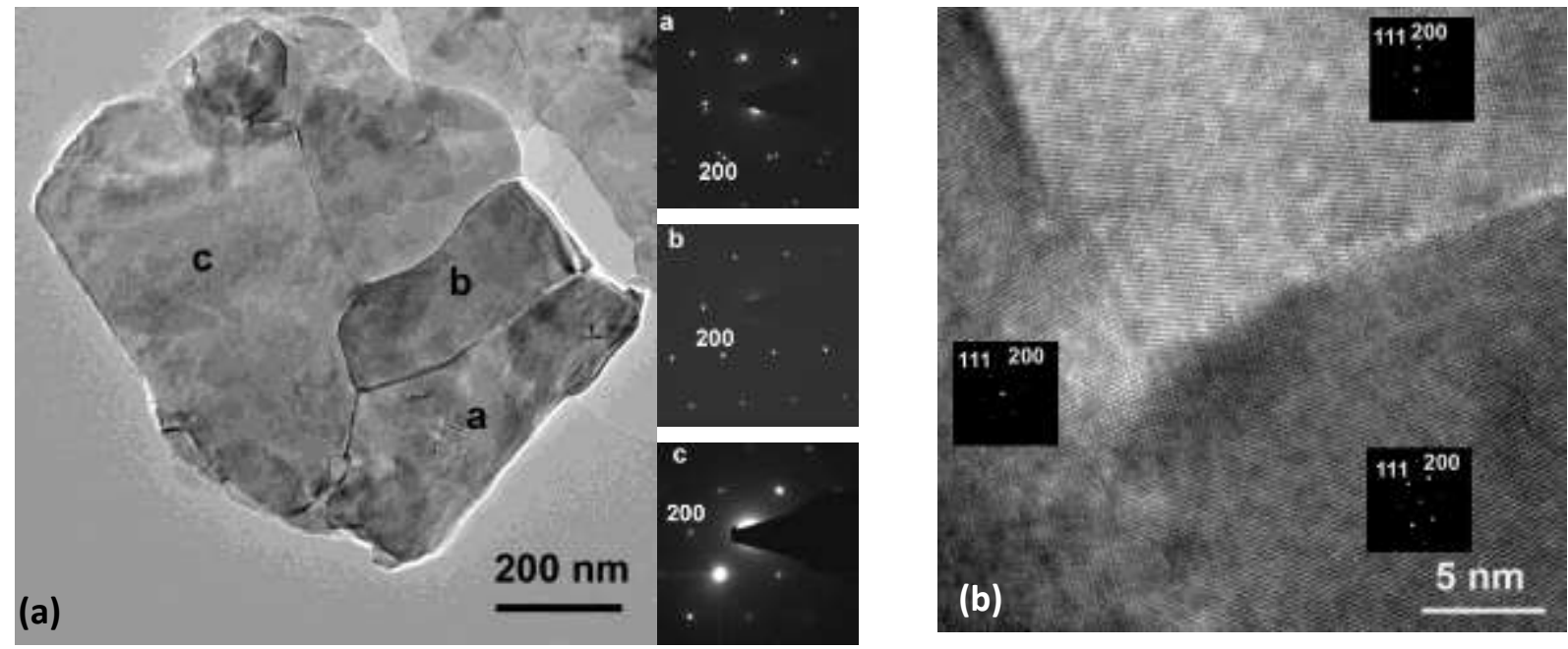

Figure 6: Microstructure of B10 powder. (a) TEM image showing that the flake is polycrystalline. The nanograins share a common $[01 \overline{1}]$ orientation as proven by the corresponding electron diffraction patterns acquired on the various grains. Grain labelled $\mathbf{a}$ and grain labeled $\mathbf{b}$ are misoriented by only $7^{\circ}$ and grain labeled $\mathbf{c}$ is in a twin relationship with grain b. (b) High resolution TEM images near to grain boundaries.

This feature has already been observed for iron nanocrystalline powders [39]. By analogy with those works, and considering the anisotropy of the tensile modulus, it can be proposed that during the ball milling procedure, Al grains are preferentially deformed in their "soft" directions. In the case of $\mathrm{Al}$, the elastic modulus is much higher for the $\{110\}$ planes than for all the others one which may explain the preferential orientation. Finally, no amorphous alumina is observed at the grain boundaries which is consistent with [24]. This could suggest that the process of crystallite formation is internal to particles and not due to welding between particles. Indeed the milling procedure is done under air which ensure that the fresh surfaces that are formed are immediately oxidized .

X-ray diffraction (XRD) was also used to analyze the structure and the microstructure of the powders. The XRD patterns are presented in Fig.7.a together with the initial powder. Only the diffraction lines of crystalline aluminum are observed for all the milled powders. This confirms that the alumina phase is still amorphous, as seen on the HRTEM images. Moreover, no crystalline impurities can be detected indicating that no major contamination took place during the milling procedure. From XRD, no preferential orientation can be evidenced since the relative intensities of the diffraction peaks are the same as the ones of the ICSD file of 
Aluminum (\#00-004-0787). Unfortunately, the $\mathrm{CuK}_{\alpha 1}$ does not allow to measure the 440 reflection of $\mathrm{Al}(\mathrm{d}=$ $0.0716 \mathrm{~nm}$ ) in order to check the anisotropy with respect with the [110] direction observed in TEM. Moreover, it should be mentioned that XRD measurements in transmission mode are less sensitive to the preferential orientation.

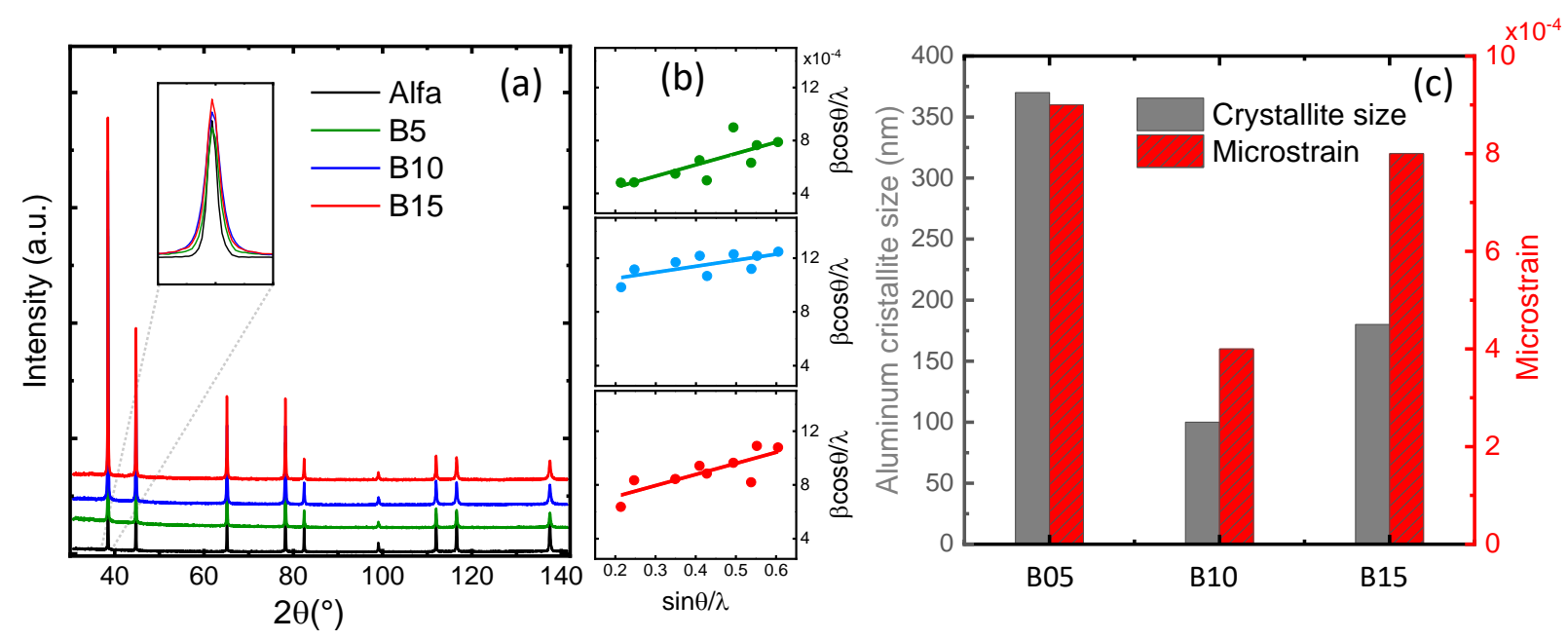

Figure 7: (a) X-ray diffraction patterns of the milled powders B05, B10 and B15 together with the initial powder Alpha. The inset shows that a significant broadening of the peaks is observed upon milling. (b) Williamson-hall plot performed to analyze the microstructure in terms of crystallite size and amount of deformation. (c) Summary of the crystallite size and deformation obtained for each powder.

The cell parameter was calculated for each powder using the Dicvol program [40] and the obtained values are given in Table 1. The lattice parameter is almost not affected by the diameter of the grinding balls. As evidenced on the inset in Fig.7.a, the peaks of the milled powders are broader than the initial one. This indicates significant changes in the microstructure of the powders such as a decrease of crystallite size and/or the onset of lattice distortions. 
Table 1 : Summary of the quantitative results obtained for each sample using various experimental methods. (1) lattice parameter obtained from XRD (2) Temperatures of the oxidation steps and the corresponding mass gain obtained from TGA. The total mass gain at $1500^{\circ} \mathrm{C}$ is used to calculate the initial $\mathrm{Al}$ content. (3) initial $\mathrm{Al}$ content obtained from volumetric titration technique. (4) Enthalpies of oxidation.

\begin{tabular}{|c|c|c|c|}
\hline & B05 & B10 & B15 \\
\hline \multicolumn{4}{|l|}{ (1) XRD analyses } \\
\hline Lattice parameter $(\AA)$ & $4.04969 \pm 0.0002$ & $4.04977 \pm 0.05$ & $4.04969 \pm 0.05$ \\
\hline \multicolumn{4}{|l|}{ (2) TGA measurements (up to $1500^{\circ} \mathrm{C}$ ) } \\
\hline Temperature $\mathrm{T}_{1}\left({ }^{\circ} \mathrm{C}\right)$ & $553 \pm 4$ & $539 \pm 3$ & $540 \pm 3$ \\
\hline Temperature $\mathrm{T}_{2}\left({ }^{\circ} \mathrm{C}\right)$ & $806 \pm 9$ & $799 \pm 1$ & $799 \pm 3$ \\
\hline Mass gain at first step, $\mathrm{M}_{1}(\%)$ & $24 \pm 2$ & $41 \pm 1$ & $37 \pm 1$ \\
\hline Mass gain at $1200^{\circ} \mathrm{C}, \mathrm{M}_{2}(\%)$ & $65 \pm 6$ & $73 \pm 2$ & $71 \pm 2$ \\
\hline Mass gain at $1500^{\circ} \mathrm{C}, \mathrm{M}_{\text {tot }}(\%)$ & $72 \pm 3$ & $72 \pm 0.3$ & $71 \pm 0.4$ \\
\hline Initial Al content determined from $\mathrm{M}_{\text {tot }}(\%)$ & $81 \pm 3$ & $81 \pm 0.3$ & $80 \pm 0.4$ \\
\hline \multicolumn{4}{|l|}{ (3) Volumetric titration technique } \\
\hline Initial Al content & $91 \pm 4$ & $85 \pm 4$ & $85 \pm 4$ \\
\hline \multicolumn{4}{|c|}{ (4) Combined DTA-TGA measurements (up to $1200^{\circ} \mathrm{C}$ ) } \\
\hline $\begin{array}{l}\text { Enthalpy } 1^{\text {st }} \text { oxidation }\left(\mathrm{kJ} / \mathrm{g}_{\mathrm{Al}}\right) \\
\left.\text { (starting the integration at } 400^{\circ} \mathrm{C}\right)\end{array}$ & $-28 \pm 1$ & $-27 \pm 4$ & $-27 \pm 2$ \\
\hline $\begin{array}{l}\text { Enthalpy } 1^{\text {st }} \text { oxidation }\left(\mathrm{kJ} / \mathrm{g}_{\mathrm{Al}}\right) \\
\left.\text { (starting the integration at } 200^{\circ} \mathrm{C}\right)\end{array}$ & $-32 \pm 1$ & $-30 \pm 2$ & $-30 \pm 2$ \\
\hline Enthalpy $2^{\text {nd }}$ oxidation $\left(\mathrm{kJ} / \mathrm{g}_{\mathrm{Al}}\right)$ & $-23 \pm 1$ & $-16 \pm 2$ & $-24 \pm 2$ \\
\hline
\end{tabular}

In order to evaluate the crystallite size and the amount of micro-strain, Williamson-Hall (WH) method was used [41]. This method consists in fitting each diffraction line with a pre-defined function in order to obtain its integral breath $\beta_{o b s}$ which is characteristic of the broadening. The diffraction lines were found to be accurately fitted by a Lorentzian function. In this case, the integral breath $\beta_{m p}$ of the milled powder is simply written $\beta_{m p}=\beta_{o b s}-\beta_{\text {inst }}$ where $\beta_{\text {inst }}$ is the instrumental broadening. The initial powder was used to estimate $\beta_{\text {inst }}$. Such an assumption can lead to a slight overestimation of the crystallite size and of the lattice distortion but gives a good idea of their relative evolution when varying the diameter of the milling balls. $\beta_{m p}$ can be expressed as a function of the crystallite size $d$ and the lattice strain $\varepsilon$ using the Williamson-Hall equation:

$$
\frac{\beta_{m p} \cos \theta}{\lambda}=\frac{1}{d}+\frac{\varepsilon \sin \theta}{\lambda}
$$

This equation corresponds to a linear relationship where the intercept is the inverse of the crystallite size and the slope is linked to lattice distortion. The Williamson-Hall plots for all the powders are shown in Fig.7(b) and the evolution of the $\mathrm{Al}$ crystallite size and microstrains are represented in the histogram of Fig.7.c. The values are within the same order of magnitude with the ones in literature $[42,43]$. The use of $5 \mathrm{~mm}$ grinding balls results in powder with the largest crystallites and deformation. An optimum is observed for B10 powder 
that possesses the smallest crystallites and the lowest amount of deformation. Those measurements together with the textural characteristics also demonstrate that texture and microstructure are directly correlated: the largest crystallites are found for thickest flakes.

\subsection{Reactivity towards oxygen}

The oxidation of the powders was first studied using TGA and the obtained thermograms are shown in Fig.8(a).
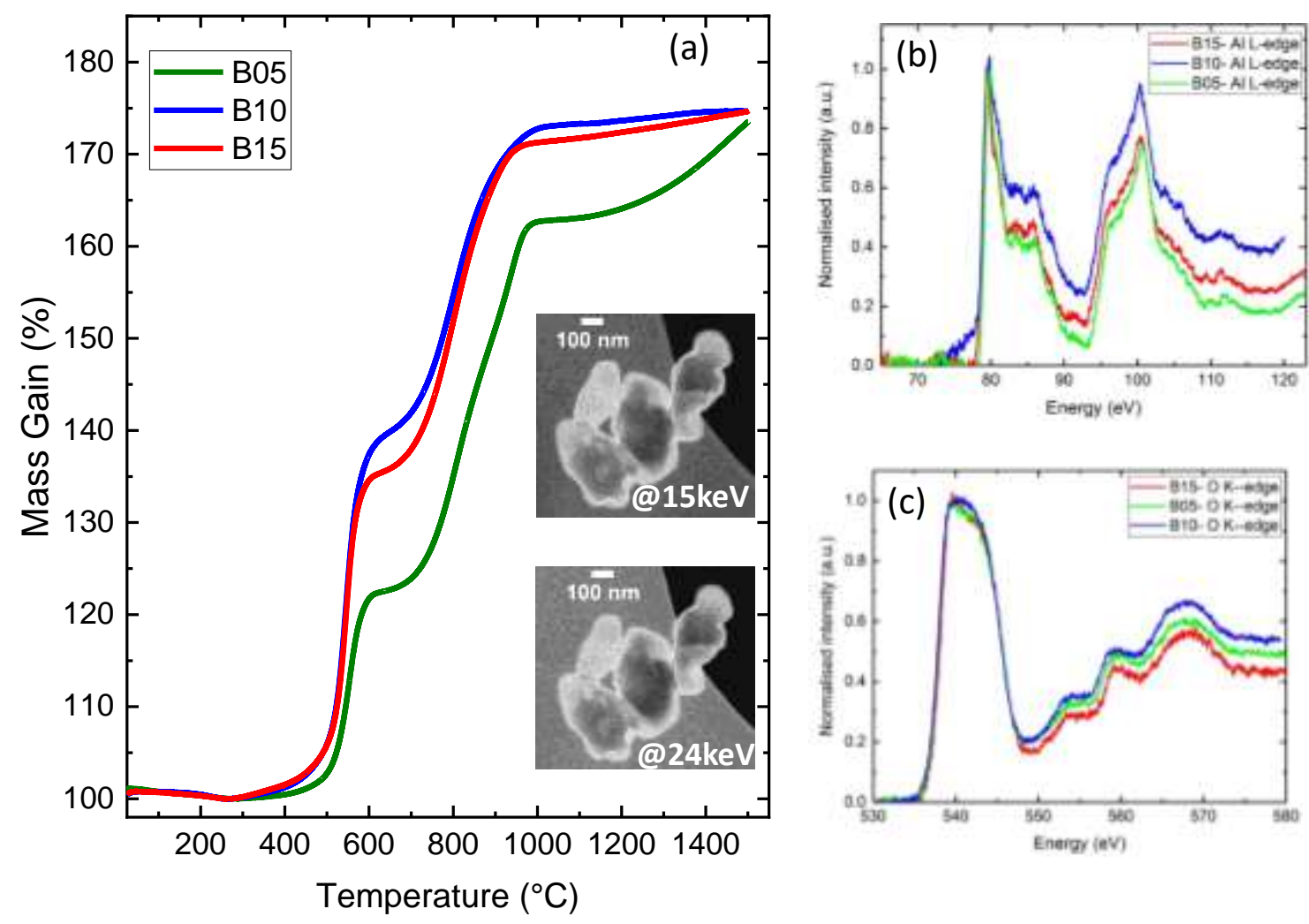

Figure 8: (a) Thermogravimetry analyses performed up to $1500^{\circ} \mathrm{C}$ on the milled powders. The samples are fully oxidized at $1500^{\circ} \mathrm{C}$ as illustrated by the EFTEM images (inset 8.a) taken on the sample B05 at $15 \mathrm{eV}$ (Al plasmon) and $22 \mathrm{eV}(\mathrm{O}$ plasmon), which show the same contrast. EELS spectra taken at the Al-L edge (b) and the O k-edge (c) for the three samples.

The well-known stepwise oxidation of aluminum nanopowders is observed here for all samples $[26,27,44,45]$. As discussed previously, it is common to derive from TGA several quantities to evaluate the reactivity of the samples. As seen in Fig.8.a, the first mass gain $\mathrm{M}_{1}$ is higher for the B10 powder and it seems to be correlated with the specific surface area since this sample has the highest one. Such correlations between specific surface area and $\mathrm{M}_{1}$ were already proposed in the case of micrometric and nanometric spherical powders [29]. However, to the best of our knowledge, it is the first time such a correlation is evidenced in flakes and within the nanometric range. Indeed, in spite of the many studies that can be found in literature on spherical 
nanopowders, it is difficult to establish any correlation between the data because TG analyses are not always done under the same experimental conditions (gas, heating rates, etc.).

The oxidation behavior between $1200^{\circ} \mathrm{C}$ and $1500^{\circ} \mathrm{C}$ is also very interesting since it also shows different characteristics depending on the powders. Whilst the mass gain increases only slightly for B10 and B15, it takes around $10 \%$ in this temperature range for B05 powders. This is expected if one considers the oxidation as a regular increase of the alumina layer at a speed that depends more on temperature than particle size: when the thickness of the obtained alumina layer is equal to half the particle height, the particle is totally oxidized. Consequently, the temperature of total oxidation is particle size dependent. Unexpectedly, the values for $\mathrm{M}_{\mathrm{tot}}$ are similar for the three samples. Indeed, due to the particle size dependence, a higher $\mathrm{M}_{\text {tot }}$ for B05 powders than for B10 and B15 powders would have been expected since a lower specific area goes well with a higher total mass gain. This suggests that the oxidation is not complete at $1500^{\circ} \mathrm{C}$ for $\mathrm{B} 05$, which is also suggested by the shape of the TGA that doesn't have reach a plateau.

TGA measurements can also be used to determine the initial metallic aluminum content. The necessary condition is that the oxidation must be complete at $1500^{\circ} \mathrm{C}$. To check if this condition was fulfilled, TEMEELS measurements were performed on the three powders. As it can be seen, the EFTEM is working well with smaller particles and at the thinner border of the bigger ones. The images acquired at $15 \mathrm{eV}$ and $24 \mathrm{eV}$ for B05 do not show any reversal of the contrasts, which indicates the absence of metallic aluminum. The EELS spectra taken at the $\mathrm{Al}$ L-edge and the $\mathrm{O}$ K-edge are given in Fig.8b and 8.c respectively. The spectra are similar for all samples indicating a same local environment around the $\mathrm{Al}$ and the $\mathrm{O}$ atoms. Moreover, according to [46], the EELS spectra at the $\mathrm{Al}$ L-edge show all the characteristic features of $\alpha-\mathrm{Al}_{2} \mathrm{O}_{3}$ for the three samples. This proves that at $1500^{\circ} \mathrm{C}$, all the alumina has crystallized into corundum phase, which is thermodynamically the most stable form of alumina.

Considering the reaction of aluminum oxidation and assuming that the mass gain in TGA is only linked to the consumption of oxygen, the mass of metallic aluminum $m_{A l}$ that has been oxidized for a given mass change $\Delta m$ can be written: 


$$
m_{A l}=\frac{4}{3} \frac{M_{A l}}{M_{O_{2}}} \Delta m
$$

with $\mathrm{M}_{\mathrm{Al}}$ and $\mathrm{M}_{\mathrm{O} 2}$ are molar mass of $\mathrm{Al}$ and $\mathrm{O}_{2}$, respectively.

The values obtained for the initial aluminum content are reported in Table 1. A very good conversion is obtained for all the powders: the initial aluminum content in all the samples is equal or higher than $80 \%$. As mentioned previously, since the oxidation may be uncompleted at $1500^{\circ} \mathrm{C}$ for $\mathrm{B} 05$, the initial aluminum content may be underestimated for this sample. This is confirmed by the results obtained using hydrogen volume released during the reaction of aluminum powders with a sodium hydroxide solution. A slightly higher purity is obtained for the B05 powder using this volumetric method. The fact that no trace of metallic aluminum is evidenced in B05 using TEM-EELS may be attributed to the size of the particles at this oxidation stage. Since the particles are far too thick in the middle, any metallic aluminum would not show any distinct spectrum due to multiple energy loss events and would only contribute to a continuous background of the oxide spectrum which stems from the thinner outer part of the particles. This also explains the weak intensity in the center of the bigger particles in the EFTEM images, as illustrated for B05 powders in the insets of Fig 8.a: the electrons suffer multiple energy losses and are not detected in the chosen energy range.

\subsection{Understanding the oxidation mechanisms}

The oxidation was also studied using combined DTA and TGA up to $1200^{\circ} \mathrm{C}$. The DSC thermograms and their corresponding TG curves are presented on Fig. 9. The TG curves are very similar to the ones obtained in TGA mode solely.

For all the powders, the heat flow presents two exothermic events that occur simultaneously to the two steps of the TG curve. They correspond to the oxidation of the $\mathrm{Al}$ core. Another less intense peak is also observed at $1150^{\circ} \mathrm{C}$ but it does not lead to any mass change which suggests that this peak is related to a phase transition. Finally, on the plateau around $650^{\circ} \mathrm{C}$, an endothermic peak corresponding to the melting of the $\mathrm{Al}$ core is observed. All those general features are consistent with the ones reported for spherical nanoparticles $[20,35,47,48]$. 


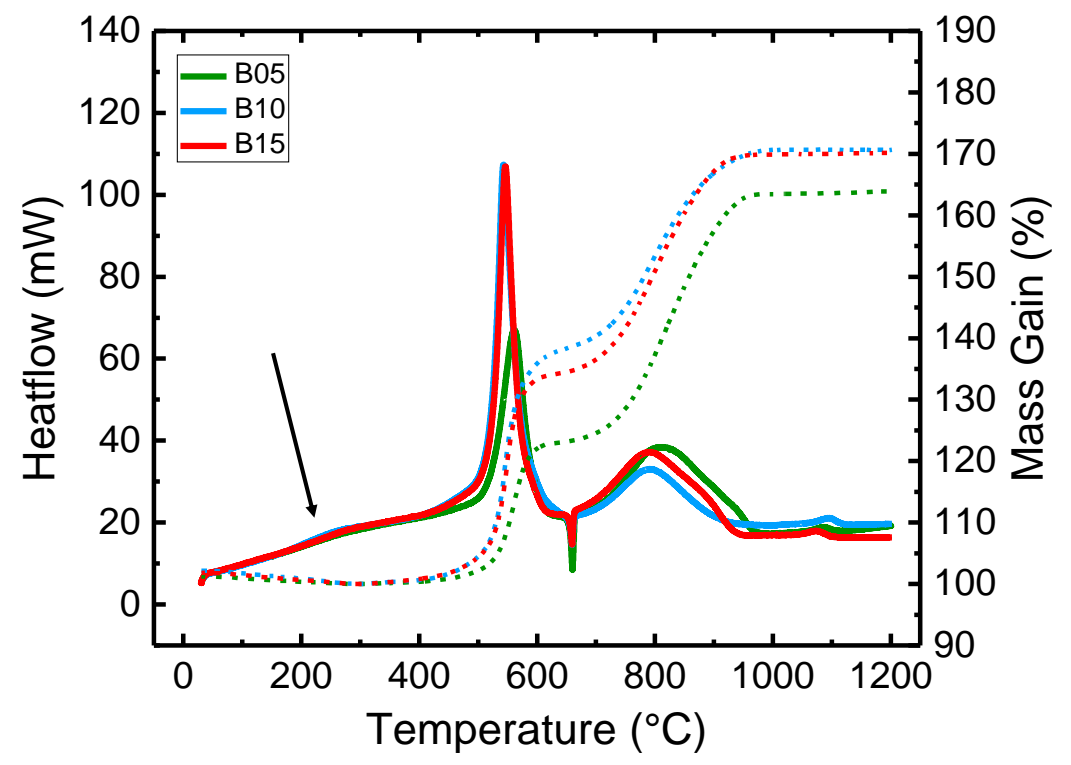

Figure 9: Combined thermogravimetry and thermal analyses performed up to $1200^{\circ} \mathrm{C}$ on the three powders.

The enthalpies and onset temperatures corresponding to the oxidation events are listed in Table 1. In order to process to the integration, the second heating cycle was used to estimate as precisely as possible the base line. Indeed, during this second cycle since the powder has been completely oxidized there is only a change of the baseline due to buoyancy. Moreover, the values are normalized according to the alumina or aluminum content at each oxidation step that can be derived from TG curves using equation (1). The normalized enthalpies of oxidation are around $27 \mathrm{~kJ} / \mathrm{g}_{\mathrm{Al}}$ which is slightly higher than the ones reported in literature for spherical powders $[20,35,49]$. However, these values are significantly lower than expected. Indeed, the enthalpy of formation for $\mathrm{Al}_{2} \mathrm{O}_{3}$ is $\Delta_{\mathrm{f}} \mathrm{H}_{298}=-1675.7 \mathrm{~kJ} / \mathrm{mol}_{\mathrm{Al2O}}$ [50] which corresponds to a value of $\Delta_{\mathrm{f}} \mathrm{H}_{298}=-31 \mathrm{~kJ} / \mathrm{g}_{\mathrm{Al}}$. To the best of our knowledge this has never been discussed in previous works on nanoparticles. Such a difference in the enthalpy of oxidation could be explained by a confinement effect. However, considering the size of the aluminum core and the expected thickness of the alumina shell at this temperature (almost the same that the initial one), confinement effects inside the $\mathrm{Al}$ core are unlikely to happen. One can wonder if the crystallographic nature of the alumina phase ( $\gamma$ in this temperature range) could explain those differences. However, the transition enthalpy between $\alpha$ and $\gamma$ is reported to be at maximum equal to $12.5 \mathrm{~kJ} / \mathrm{mol}(=0.2$ $\mathrm{kJ} / \mathrm{g}_{\mathrm{Al}}$ ) for nanoparticles and thus this cannot be the only mechanism explaining those differences. A detailed inspection of the heat flow shows that the exothermic event could be considered to start at much lower 
temperatures: a clear shoulder is observed on the heat flow around $200^{\circ} \mathrm{C}$ (see arrow on Fig.9). In the previously cited literature, there is also a broad exothermic effect in the presented thermograms. The fact that no mass gain is observed in this region is probably linked to the desorption of organic species and loss of surface $\mathrm{OH}$ groups that mask any mass gain in this region. If one considers this shoulder around $200^{\circ} \mathrm{C}$ as the beginning of the exothermic peak, the integration lead to values very close to $30 \mathrm{~kJ} / \mathrm{g}$ for the three samples (see Table 1). This suggests that the oxidation of the aluminum core is starting well before the first step in the TGA curve: the amorphous alumina layer starts growing around $200^{\circ} \mathrm{C}$. At low temperatures, both diffusion of oxygen and aluminum are reported to occur. On one hand, one can hypothesize that the amorphous nature of the alumina favors the diffusion of the oxygen atoms at such low temperature. On the other hand, the polycrystalline nature of the aluminum core may allow the diffusion of $\mathrm{Al}^{3+}$ species. These hypotheses are supported by the fact that the oxidation starts at lower temperatures for B10, which is the sample having the smallest crystallites which means the highest density of grain boundaries. Once the alumina layer has reached its critical value, it crystallizes and leads to the first mass step around $450^{\circ} \mathrm{C}$, because the changes in density make aluminum surface more accessible. Here again, there is a clear difference between the samples since the critical thickness is reached at lower temperature for B10 sample.

A high temperature, i.e. in the temperature range 600-1200 corresponding to the second step, a relatively poor agreement is found between the measured enthalpy of oxidation and the tabulated value. However, once again the measured values are in good agreement with literature. At this oxidation stage, confinement effects are likely to occur since the alumina shell thickness may reach values above $30 \mathrm{~nm}$ [51]. Further experiment and modeling are needed to propose some hypothesis about this important decrease of oxidation enthalpy.

\section{Conclusion}

In this study, aluminum powders were synthesized using high-energy ball-milling. Their texture, microstructure and thermal properties were examined. The particles have a flake morphology, and depending on the diameter of the grinding balls, the specific surface area can vary from 11 up to $22 \mathrm{~m}^{2} / \mathrm{g}$. While the particle lengths and widths are similar for all the powders, the thickness of the particles strongly varies with the diameter of the grinding balls. The thinnest particles have been synthetized with $10 \mathrm{~mm}$ balls. The coreshell $\mathrm{Al}_{2} \mathrm{O}_{3} / \mathrm{Al}$ structure of the particles is observed for all the powders, but the thickness of the alumina shell 
is not as homogeneous as commonly observed in spherical particles. The aluminum core is always polycrystalline and preferentially [110] oriented but the crystallite size and the amount of deformation is also depending on the ball diameter. These various structural characteristics are shown to have a direct influence on the thermal behavior under oxidative atmosphere. The first oxidation step occurs at a lower temperature for the powders having the larger specific surface area, which confirms the tendency already observed between micron and nanometric particles. For powders having similar textural properties (B10 and B15), one can observe that the B10 powder, which presents the smallest crystallite sizes and microstrain amount, starts to oxidize before the B15 powder. This work could help to design the most efficient powder for energetic materials applications: it should be polycrystalline with crystallites as small as possible to favorize a complete oxidation and it should possess a thick but still amorphous alumina layer to decrease the ignition temperature.

\section{Acknowledgements}

This work has been carried out thanks to the support of the Délégation Générale des Armées (DGA) via the ASTRID program managed by the French National Research Agency (Project number ANR-13-ASTR-0032). The DGA and Aix-Marseille Université are strongly acknowledged for funding the PhD grant of P.-H.E.

\section{References}

[1] A. Kumar, D.G. Madden, M. Lusi, K.-J. Chen, E.A. Daniels, T. Curtin, J.J. Perry, M.J. Zaworotko, Direct Air Capture of $\mathrm{CO}_{2}$ by Physisorbent Materials, Angewandte Chemie International Edition. 54 (2015) 14372-14377. https://doi.org/10.1002/anie.201506952.

[2] G.S. Sodhi, J. Kaur, Powder method for detecting latent @ngerprints: a review, Forensic Science International. (2001) 5 .

[3] P.M. Karlsson, A. Baeza, A.E.C. Palmqvist, K. Holmberg, Surfactant inhibition of aluminium pigments for waterborne printing inks, Corrosion Science. 50 (2008) 2282-2287. https://doi.org/10.1016/j.corsci.2008.06.014.

[4] T.S. Sverak, C.G.J. Baker, O. Kozdas, Efficiency of grinding stabilizers in cement clinker processing, Minerals Engineering. 43-44 (2013) 52-57. https://doi.org/10.1016/j.mineng.2012.08.012.

[5] H. Nie, M. Schoenitz, E.L. Dreizin, Calorimetric investigation of the aluminum-water reaction, International Journal of Hydrogen Energy. 37 (2012) 11035-11045. https://doi.org/10.1016/j.ijhydene.2012.05.012. 
[6] K. Shimamura, F. Shimojo, R.K. Kalia, A. Nakano, K. Nomura, P. Vashishta, Hydrogen-on-Demand Using Metallic Alloy Nanoparticles in Water, Nano Lett. 14 (2014) 4090-4096. https://doi.org/10.1021/nl501612v.

[7] E. Lafontaine, M. Comet, Nanothermites, John Wiley \& Sons ; ISTE Ltd, Hoboken, New Jersey: London, 2016.

[8] Q. Nguyen, C. Huang, M. Schoenitz, K.T. Sullivan, E.L. Dreizin, Nanocomposite thermite powders with improved flowability prepared by mechanical milling, Powder Technology. 327 (2018) 368-380. https://doi.org/10.1016/j.powtec.2017.12.082.

[9] D.E.G. Jones, R. Turcotte, R.C. Fouchard, Q.S.M. Kwok, A.-M. Turcotte, Z. Abdel-Qader, Hazard Characterization of Aluminum Nanopowder Compositions, Propellants, Explosives, Pyrotechnics. 28 (2003) 120-131. https://doi.org/10.1002/prep.200390018.

[10] S.M. Pourmortazavi, S.S. Hajimirsadeghi, I. Kohsari, M. Fathollahi, S.G. Hosseini, Thermal decomposition of pyrotechnic mixtures containing either aluminum or magnesium powder as fuel, Fuel. 87 (2008) 244-251. https://doi.org/10.1016/j.fuel.2007.04.022.

[11] W.K. Lewis, C.G. Rumchik, M.J. Smith, K.A.S. Fernando, C.A. Crouse, J.E. Spowart, E.A. Guliants, C.E. Bunker, Comparison of post-detonation combustion in explosives incorporating aluminum nanoparticles: Influence of the passivation layer, Journal of Applied Physics. 113 (2013) 044907. https://doi.org/10.1063/1.4790159.

[12] S. Verma, P.A. Ramakrishna, Effect of Specific Surface Area of Aluminum on Composite Solid Propellant Burning, Journal of Propulsion and Power. 29 (2013) 1200-1206. https://doi.org/10.2514/1.B34772.

[13] F. Maggi, S. Dossi, C. Paravan, L.T. DeLuca, M. Liljedahl, Activated aluminum powders for space propulsion, Powder Technology. 270 (2015) 46-52. https://doi.org/10.1016/j.powtec.2014.09.048.

[14] L.T. De Luca, L. Galfetti, F. Severini, L. Meda, G. Marra, A.B. Vorozhtsov, V.S. Sedoi, V.A. Babuk, Burning of Nano-Aluminized Composite Rocket Propellants, Combust Explos Shock Waves. 41 (2005) 680-692. https://doi.org/10.1007/s10573-005-0080-5.

[15] Y.-S. Kwon, Y.-H. Jung, N.A. Yavorovsky, A.P. Illyn, J.-S. Kim, Ultra-fine powder by wire explosion method, Scripta Materialia. 44 (2001) 2247-2251. https://doi.org/10.1016/S1359-6462(01)00757-6.

[16] P. Sen, J. Ghosh, A. Abdullah, P. Kumar, Vandana, Preparation of $\mathrm{Cu}, \mathrm{Ag}, \mathrm{Fe}$ and $\mathrm{Al}$ nanoparticles by the exploding wire technique, J Chem Sci. 115 (2003) 499-508. https://doi.org/10.1007/BF02708241.

[17] T.K. Sindhu, R. Sarathi, S.R. Chakravarthy, Generation and characterization of nano aluminium powder obtained through wire explosion process, Bull Mater Sci. 30 (2007) 187-195. https://doi.org/10.1007/s12034-007-0034-5.

[18] T. Laha, K. Balani, A. Agarwal, S. Patil, S. Seal, Synthesis of nanostructured spherical aluminum oxide powders by plasma engineering, Metall and Mat Trans A. 36 (2005) 301-309. https://doi.org/10.1007/s11661-005-0303-0. 
[19] A. Pivkina, D. Ivanov, Y. Frolov, S. Mudretsova, A. Nickolskaya, J. Schoonman, Plasma synthesized nano-aluminum powders Structure, thermal properties and combustion behavior, (2006) 6 .

[20] F. Wang, Z. Wu, X. Shangguan, Y. Sun, J. Feng, Z. Li, L. Chen, S. Zuo, R. Zhuo, P. Yan, Preparation of mono-dispersed, high energy release, core/shell structure $\mathrm{Al}$ nanopowders and their application in HTPB propellant as combustion enhancers, Sci Rep. 7 (2017) 5228. https://doi.org/10.1038/s41598017-05599-0.

[21] L. Guo, W. Song, C. Xie, X. Zhang, M. Hu, Characterization and thermal properties of carbon-coated aluminum nanopowders prepared by laser-induction complex heating in methane, Materials Letters. 61 (2007) 3211-3214. https://doi.org/10.1016/j.matlet.2006.11.035.

[22] L. Chen, D. Zhang, Z. Wang, T. Wei, S. Wang, Thermal property and structure of aluminium nanoparticles produced by different methods, Materials Research Innovations. 18 (2014) S2-595-S2599. https://doi.org/10.1179/1432891714Z.000000000534.

[23] E.L. Dreizin, M. Schoenitz, Mechanochemically prepared reactive and energetic materials: a review, J Mater Sci. 52 (2017) 11789-11809. https://doi.org/10.1007/s10853-017-0912-1.

[24] B. André, M.-V. Coulet, P.-H. Esposito, B. Rufino, R. Denoyel, High-energy ball milling to enhance the reactivity of aluminum nanopowders, Materials Letters. 110 (2013) 108-110. https://doi.org/10.1016/j.matlet.2013.07.101.

[25] N. Eisenreich, H. Fietzek, M. del Mar Juez-Lorenzo, V. Kolarik, A. Koleczko, V. Weiser, On the Mechanism of Low Temperature Oxidation for Aluminum Particles down to the Nano-Scale, Propellants, Explosives, Pyrotechnics. 29 (2004) 137-145. https://doi.org/10.1002/prep.200400045.

[26] M.A. Trunov, M. Schoenitz, X. Zhu, E.L. Dreizin, Effect of polymorphic phase transformations in Al2O3 film on oxidation kinetics of aluminum powders, Combustion and Flame. 140 (2005) 310-318. https://doi.org/10.1016/j.combustflame.2004.10.010.

[27] L. Chen, W.L. Song, J. Lv, L. Wang, C.S. Xie, Effect of heating rates on TG-DTA results of aluminum nanopowders prepared by laser heating evaporation, J Therm Anal Calorim. 96 (2009) 141-145. https://doi.org/10.1007/s10973-008-9374-7.

[28] Y.-S. Kwon, J.-S. Moon, A.P. Ilyin, A.A. Gromov, E.M. Popenko, Estimation of the reactivity of aluminum superfine powders for energetic applications, Combustion Science and Technology. 176 (2004) 277-288. https://doi.org/10.1080/00102200490255992.

[29] B. Rufino, F. Boulc'h, M.-V. Coulet, G. Lacroix, R. Denoyel, Influence of particles size on thermal properties of aluminium powder, Acta Materialia. 55 (2007) 2815-2827. https://doi.org/10.1016/j.actamat.2006.12.017.

[30] B. André, M.V. Coulet, M. Dumont, J. Rogez, V. Heresanu, B. Rufino, R. Bouchet, R. Denoyel, Morphology and reactivity of aluminium nanocrystalline powders, IJNT. 9 (2012) 618. https://doi.org/10.1504/IJNT.2012.045332.

[31] C. Suryanarayana, Mechanical alloying and milling, Progress in Materials Science. (2001) 184. 
[32] A.R. Othman, A. Sardarinejad, A.K. Masrom, Effect of milling parameters on mechanical alloying of aluminum powders, Int J Adv Manuf Technol. 76 (2015) 1319-1332. https://doi.org/10.1007/s00170014-6283-8.

[33] S.S. Razavi-Tousi, J.A. Szpunar, Effect of ball size on steady state of aluminum powder and efficiency of impacts during milling, Powder Technology. 284 (2015) 149-158. https://doi.org/10.1016/j.powtec.2015.06.035.

[34] S. Khorasani, H. Abdizadeh, S. Heshmati-Manesh, Evaluation of structure and morphology of aluminum powder particles milled at different conditions, Advanced Powder Technology. 25 (2014) 599-603. https://doi.org/10.1016/j.apt.2013.09.011.

[35] S.A. Antipina, S.V. Zmanovskii, A.A. Gromov, U. Teipel, Air and water oxidation of aluminum flake particles, Powder Technology. 307 (2017) 184-189. https://doi.org/10.1016/j.powtec.2016.12.009.

[36] M. Thommes, K. Kaneko, A.V. Neimark, J.P. Olivier, F. Rodriguez-Reinoso, J. Rouquerol, K.S.W. Sing, Physisorption of gases, with special reference to the evaluation of surface area and pore size distribution (IUPAC Technical Report), Pure and Applied Chemistry. 87 (2015) 1051-1069. https://doi.org/10.1515/pac-2014-1117.

[37] D.E.G. Jones, P. Brousseau, R.C. Fouchard, A.M. Turcotte, Q.S.M. Kwok, Thermal Characterization of Passivated Nanometer Size Aluminium Powders, (2000) 14.

[38] Y.-S. Kwon, A.A. Gromov, J.I. Strokova, Passivation of the surface of aluminum nanopowders by protective coatings of the different chemical origin, Applied Surface Science. 253 (2007) 5558-5564. https://doi.org/10.1016/j.apsusc.2006.12.124.

[39] D. Amador, Morphological and microstructural characterisation of low-alloying Fe powder obtained by mechanical attrition, Journal of Materials Processing Technology. 143-144 (2003) 776-780. https://doi.org/10.1016/S0924-0136(03)00372-8.

[40] A. Boultif, D. Louër, Powder pattern indexing with the dichotomy method, J Appl Crystallogr. 37 (2004) 724-731. https://doi.org/10.1107/S0021889804014876.

[41] G.K. Williamson, W.H. Hall, X-ray line broadening from filed aluminium and wolfram, Acta Metallurgica. 1 (1953) 22-31. https://doi.org/10.1016/0001-6160(53)90006-6.

[42] R. Daly, M. Khitouni, A.W. Kolsi, N. Njah, The studies of crystallite size and microstrains in aluminum powder prepared by mechanical milling, Phys. Stat. Sol. (c). 3 (2006) 3325-3331. https://doi.org/10.1002/pssc.200567112.

[43] R.J. Jacob, K.J. Hill, Y. Yang, M.L. Pantoya, M.R. Zachariah, Pre-stressing aluminum nanoparticles as a strategy to enhance reactivity of nanothermite composites, Combustion and Flame. 205 (2019) 3340. https://doi.org/10.1016/j.combustflame.2019.03.024.

[44] E.L. Dreizin, Metal-based reactive nanomaterials, Progress in Energy and Combustion Science. 35 (2009) 141-167. https://doi.org/10.1016/j.pecs.2008.09.001. 
[45] B. Rufino, M.-V. Coulet, R. Bouchet, O. Isnard, R. Denoyel, Structural changes and thermal properties of aluminium micro- and nano-powders, Acta Materialia. 58 (2010) 4224-4232. https://doi.org/10.1016/j.actamat.2010.04.014.

[46] D. Bouchet, C. Colliex, Experimental study of ELNES at grain boundaries in alumina: intergranular radiation damage effects on Al-L23 and O-K edges, Ultramicroscopy. 96 (2003) 139-152. https://doi.org/10.1016/S0304-3991(02)00437-0.

[47] Y. Sun, R. Sun, B. Zhu, K. Mao, Y. Wu, Thermal reaction mechanisms of nano- and micro-scale aluminum powders in carbon dioxide at low heating rate, J Therm Anal Calorim. 124 (2016) 17271734. https://doi.org/10.1007/s10973-016-5284-2.

[48] A. Gromov, U. Teipel, Nanoaluminium: is there any Relationship between Powder Particles' Size, Non-Isothermal Oxidation Data and Ballistics?, Cent. Eur. J. Energ. Mater. 14 (2017) 501-519. https://doi.org/10.22211/cejem/73825.

[49] A. Gromov, A. Ilyin, U. Förter-Barth, U. Teipel, Characterization of Aluminum Powders: II. Aluminum Nanopowders Passivated by Non-Inert Coatings, Prop., Explos., Pyrotech. 31 (2006) 401409. https://doi.org/10.1002/prep.200600055.

[50] E.A. Brandes, G.B. Brook, C.J. Smithells, eds., Smithells metals reference book, 7th ed / edited by E.A. Brandes and G.B. Brook, Butterworth-Heinemann, Oxford ; Boston, 1998.

[51] M.-V. Coulet, B. Rufino, P.-H. Esposito, T. Neisius, O. Isnard, R. Denoyel, Oxidation Mechanism of Aluminum Nanopowders, J. Phys. Chem. C. 119 (2015) 25063-25070. https://doi.org/10.1021/acs.jpcc.5b07321. 